\title{
Time-Dependent Effects of Intrahypothalamic Injection of Vasoactive Intestinal Peptide on Spontaneous Motor Activity in Rats
}

\author{
Ryuhei Hashimoto, ${ }^{*}$ Chucheep Praputpittaya, \\ and Fukuko Kimura \\ Department of Physiology, Yokohama City University \\ School of Medicine, Yokohama, 236 Japan
}

\begin{abstract}
In male Wistar rats, microinjection cannulae were stereotaxically implanted in the ventromedial and paraventricular hypothalamic nuclei. After control recordings of spontaneous motor activity for 4-6 days, vasoactive intestinal peptide (VIP) was injected in a dose of $1.0 \mu \mathrm{g}$ and a volume of $2.0 \mu \mathrm{l}$ into these nuclei at 1100 or $1900 \mathrm{~h}$, and the activity during the 3 -h period following was compared with that on the control days in individual animals. VIP injection produced an increase when injected at $1100 \mathrm{~h}$, and a decrease when injected at $1900 \mathrm{~h}$. Thus, a timedependent fluctuation in the VIP effect on the hypothalamic neuronal activity was suggested.
\end{abstract}

Key words: spontaneous motor activity, circadian rhythm, vasoactive intestinal peptide, hypothalamic microinjection, rats.

It has recently been reported that an intracerebroventricular administration of vasoactive intestinal peptide (VIP) shortens the duration of pentobarbital-induced sleep and produces significant hypermotility in the rat, indicating that this peptide plays some role in the manifestation of behavior (ITOH et al., 1985).

On the other hand, the hypothalamic nuclei such as the ventromedial and paraventricular hypothalamic nuclei (VM and PV, respectively) were identified as being effective sites for eliciting overeating and increased body weight, when lesioned (Heinbecker et al., 1944; Grossman, 1975; Rowley, 1977; Leibowitz et al., 1981), indicating the involvement of these regions in the control of feeding behavior. Furthermore, it has been indicated that the VM is an important center for the behavioral response to a variety of stimuli. In addition to causing overeating, the lesion causes in rats exaggerated responses to sensory stimuli, i.e., the increase in aggressive behavior, avoidance behavior, and locomotor activity (GrossMAN, 1972; SEPINWALL, 1969), which have been attributed to increased affectivity (WEISMAN

Received for publication March 14, 1989

* To whom all correspondence should be addressed. 
and HAMILTON, 1972), a reduction in fear (COLPAERT, 1975), increased sensitivity to pain (Grossman, 1972), and so on. The increased locomotor activity occurred even in a novel environment (SEPINWALL, 1969).

Therefore, in the present experiments, the effects of injection of VIP into the VM and PV on spontaneous motor activity were studied in order to examine whether these regions are the site of action of VIP. Further, whether the effect differed according to the time of injection was also examined since a time-dependent fluctuation was reported previously concerning the effects on the feeding behavior of norepinephrine administered in the lateral hypothalamus (MARGules et al., 1972).

\section{MATERIALS AND METHODS}

Animals. Male Wistar rats, weighing approximately $300 \mathrm{~g}$, were housed at a constant temperature of $25 \mathrm{C}$ under a 14-h/10-h light-dark cycle (lights on 0500-1900 h), with food and water available ad libitum.

Surgery. A total of 29 animals were anesthetized with sodium pentobarbital, and then were implanted unilaterally with the guide cannulae made of a stainless steel tube with a $0.65 \mathrm{~mm}$ outer diameter into the hypothalamus, according to the atlas of AlBE-FESSARD et al. (1966). The coordinates were as follows: for the PV, $A=6.6, L=0.5, V=3.3$; for the VM, $A=6.6, L=0.5, V=2.0$. The cannulae were fixed to the skull with dental cement and stainless steel screws. The inner cannula with a $0.30 \mathrm{~mm}$ outer diameter was arranged so as to protrude approximately $0.5 \mathrm{~mm}$ beyond the tip of the guide cannula.

Peptide injection. VIP was injected into the hypothalamic nuclei in a dose of $1.0 \mu \mathrm{g}$ (about $0.3 \mathrm{nmol}$ ) and a volume of $2.0 \mu \mathrm{l}$ using a $10 \mu \mathrm{l}$ microsyringe attached to the inner cannula with Silastic tubing at the speed $1.0 \mu \mathrm{l} / \mathrm{min}$. Synthetic VIP was purchased from the Peptide Institute, Minoo, Japan. It was initially dissolved in $0.001 \mathrm{M} \mathrm{HCl}$ and diluted with saline to obtain the final concentration. The dose $1.0 \mu \mathrm{g}$ was reported to be minimally effective to produce hypermotility when injected intracerebroventricularly (Iтон et al., 1985).

Spontaneous motor activity. Two weeks after the implantation of the guide cannula, each animal in the individual cage was transferred to an experimental chamber, in which the same light-dark cycle was maintained as before. Spontaneous motor activity was measured with an Automex (Columbus Instruments), an instrument that displays magnetic field counts corresponding to increased activity of the rat in the cage, and the counts were recorded every 30 min. After recording for 4-6 days during which no drugs were injected (therefore, designated as control days), each animal was tested with an intrahypothalamic injection of saline $(2.0 \mu \mathrm{l})$ or VIP. The injection was performed at $1100 \mathrm{~h}$ for the light-cycle test or $1900 \mathrm{~h}$ for the dark-cycle test, and the recording was continued for another $8 \mathrm{~h}, 16 \mathrm{~h}$, or more. Although it was a rule that every animal received both the light- and dark-cycle tests for saline, all the animals did not necessarily receive both tests for VIP. Further, the 
experiment was discontinued if an animal did not show an apparent circadian rhythm in the activity for some reason on control days. This occurred in 4 rats.

Histology and statistical analysis. After the recording experiment was finished, all the animals were anesthetized with ether and perfused with $10 \%$ buffered formalin. The site of injection was microscopically identified in $40 \mu \mathrm{m}$ sections stained with cresyl violet.

The evaluation of the effect of peptide on the motor activity was performed for each injection by comparing the total activity count during the 3 -h period following the injection, i.e., $1100-1400 \mathrm{~h}$ or $1900-2200 \mathrm{~h}$, with the mean of the total activity count during the corresponding 3 -h period on the control days in the same animal. That is, if the activity count during the 3 -h period after saline or peptide injection was increased or decreased beyond 2 S.D. of the mean activity count during the corresponding 3-h period on the 4-6 control days, the effect of saline or peptide was evaluated as facilitation or inhibition, respectively. Data from 3 animals which showed a facilitation in response to saline as well as to VIP during light cycle were eliminated from further analysis, since such response to VIP was assumed to be nonspecific. Additional evaluation was performed similarly for the total activity count during the 10 -h period in the dark cycle.

\section{RESULTS}

A total of 33 injections of VIP, which were performed in 22 rats, were evaluated for the effect on motor activity as described before. Each evaluation is shown in Fig. 1, with respect to the site of injection. Further, these results are summarized in Table 1, whith respect to each of the hypothalamic nuclei, i.e., the VM and PV, and other regions, i.e., anterior hypothalamic area (AHA) and dorsomedial

Table 1. Effect of VIP injection in the hypothalamic nuclei on spontaneous motor activity.

\begin{tabular}{|c|c|c|c|c|c|c|c|c|}
\hline \multirow{3}{*}{ Sites } & \multicolumn{8}{|c|}{ Time of injection } \\
\hline & \multicolumn{4}{|c|}{ Light cycle $(1100 \mathrm{~h})$} & \multicolumn{4}{|c|}{ Dark cycle $(1900$ h) } \\
\hline & $\begin{array}{l}\text { No. of } \\
\text { injec- } \\
\text { tions }\end{array}$ & $\begin{array}{l}\text { Facili- } \\
\text { tation }\end{array}$ & $\begin{array}{l}\text { No } \\
\text { change }\end{array}$ & $\begin{array}{l}\text { Inhibi- } \\
\text { tion }\end{array}$ & $\begin{array}{l}\text { No. of } \\
\text { injec- } \\
\text { tions }\end{array}$ & $\begin{array}{l}\text { Facili- } \\
\text { tation }\end{array}$ & $\begin{array}{l}\text { No } \\
\text { change }\end{array}$ & $\begin{array}{l}\text { Inhibi- } \\
\text { tion }\end{array}$ \\
\hline PV & 5 & $4^{*}$ & 1 & 0 & 4 & 0 & 1 & 3 \\
\hline VM & 11 & 8 & 3 & 0 & 6 & 1 & 2 & 3 \\
\hline AHA & 3 & 0 & 3 & 0 & 0 & 0 & 0 & 0 \\
\hline $\mathrm{DM}$ & 3 & 0 & 1 & 2 & 1 & 0 & 0 & 1 \\
\hline
\end{tabular}

* Indicates the number of injections that produced facilitation, no change, or inhibition. 

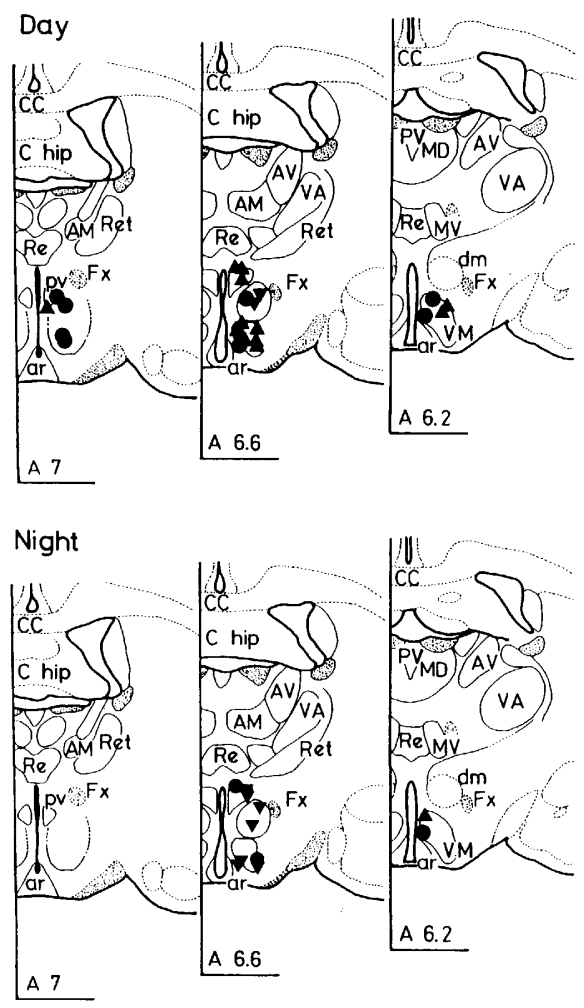

Fig. 1. Schematic illustration showing the site of the tip of the cannula in the brain. According to the effect of peptide on the spontaneous motor activity, the site is shown by for facilitation $(\boldsymbol{\Lambda})$, for inhibition $(\boldsymbol{\nabla})$, or for no change $(\bullet)$. The illustrations are modified from the atlas of ALBE-FESSARD et al. (1966). Abbreviations: ar, arcuate nucleus; $\mathrm{CC}$, corpus callosum; $\mathrm{C}$ hip, corpus hippocampi; DM, dorsomedial hypothalamic nucleus; Fx, fornix; PV, paraventricular hypothalamic nucleus; VM, ventromedial hypothalamic nucleus.

hypothalamic nucleus (DM), in which several cannulae were located unexpectedly.

Twelve $(75 \%)$ of 16 injections of VIP in the VM and PV performed at $1100 \mathrm{~h}$ produced an increase in motor activity in the 3 -h period afterward. The mean ( \pm S.E.) of the increase rate produced by the 12 injections was $308 \pm 53 \%$, when compared to the mean activity count during the corresponding period on control days. However, the injection at $1900 \mathrm{~h}$ produced a reduction to $40 \pm 12 \%$ in $6(60 \%)$ of 10 rats injected. Only one injection, which was performed rather in a more caudal part of the VM than in others, caused an increase. Such time-dependent difference in the VIP effect was significant as analyzed by chi-square test for both the VM and PV (chi-square $(2)=14.857, p<0.001$ ), and also for each of the VM (chisquare $(2)=7.853, p<0.05$ ) and the PV (chi-square $(2)=6.975, p<0.05$ ). Three 


\section{VM (144)}

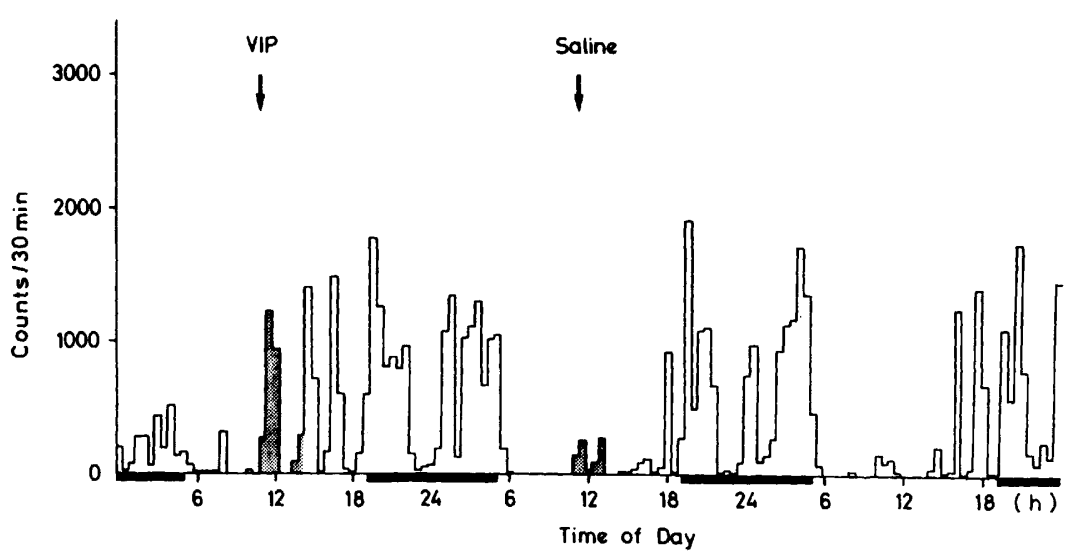

VM (186)

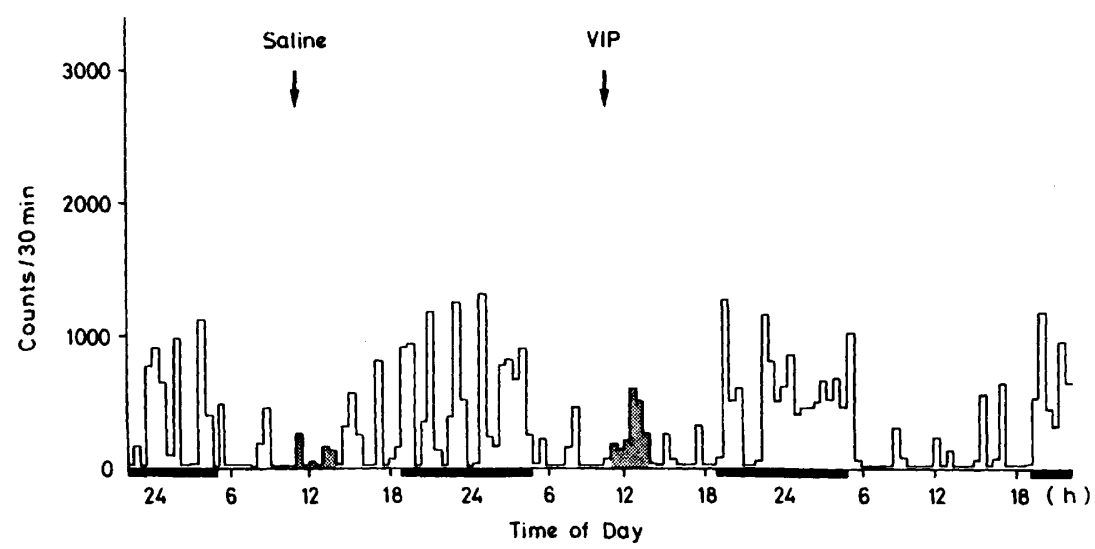

Fig. 2. Representative profiles of spontaneous motor activity recorded in individual animals. Facilitatory effects of VIP injected in the VM at $1100 \mathrm{~h}$ on the activity counts in the 3-h period afterward (shaded area) are shown. Numbers in the parentheses indicate the rat No. Black sections in the horizontal bar indicate the dark cycle $(1900-0500 \mathrm{~h})$ and arrows indicate the injection.

injections in the AHA performed at $1100 \mathrm{~h}$ did not cause a significant effect, while 3 of 4 injections in the DM produced an inhibition regardless of the time they were performed.

In Figs. 2 and 3, representative profiles of spontaneous motor activity recorded in individual animals are shown. In rat Nos. 144 and 186 (Fig. 2), VIP injection into the $\mathrm{VM}$ at $1100 \mathrm{~h}$ produced a significant increase in the activity during the period $1100-1400 \mathrm{~h}$ (in rat No. 144, 843 counts in the period $1100-1400 \mathrm{~h}$ after saline injection whereas 1,513 counts after VIP; in rat No. 186, 666 counts after saline and 


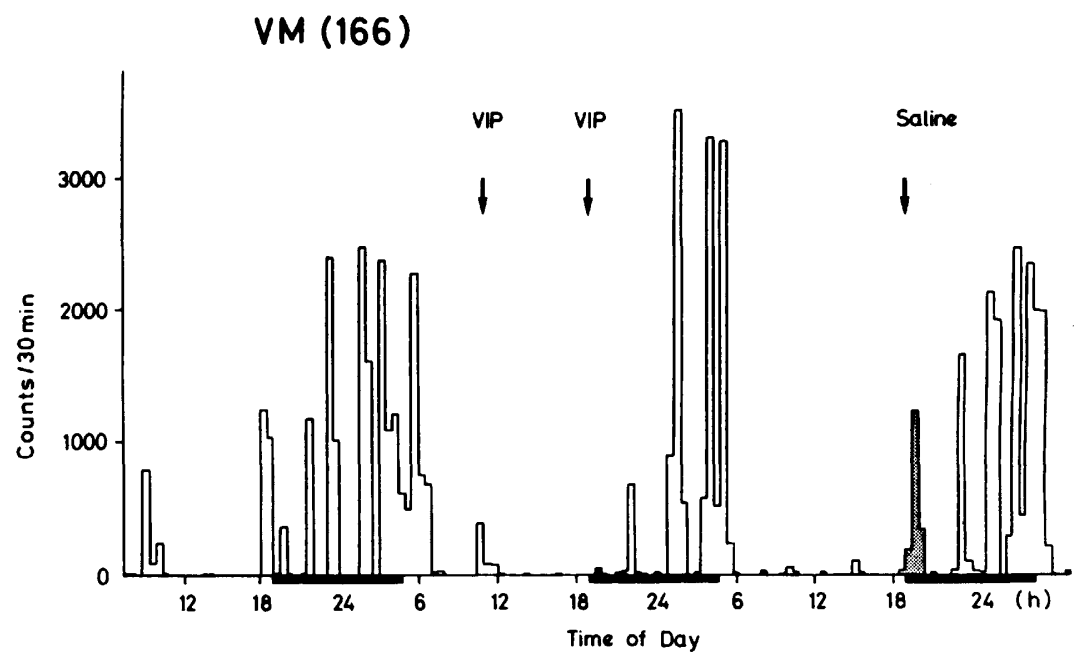

PV (187)

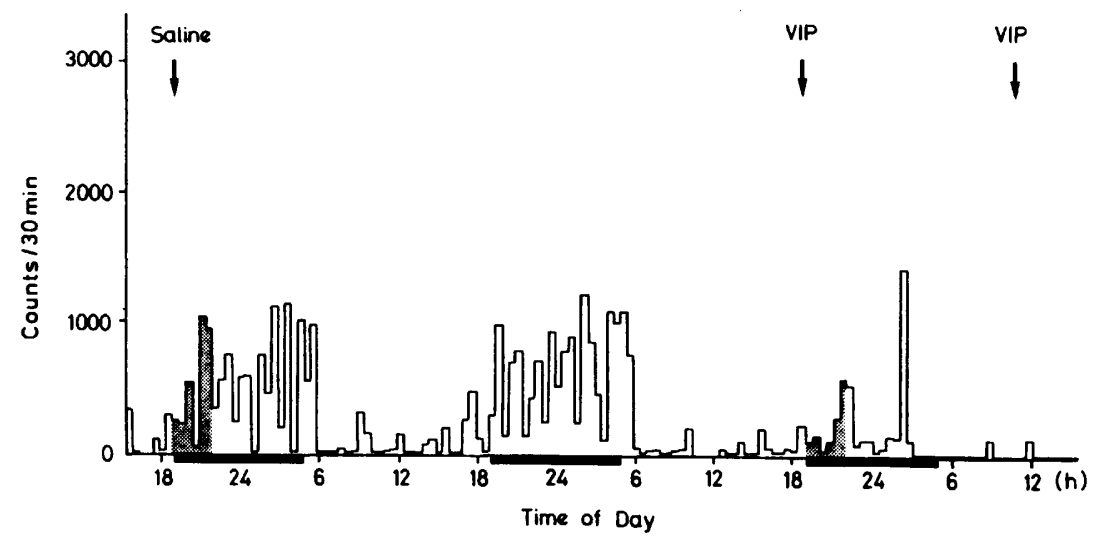

Fig. 3. Representative profiles of spontaneous motor activity recorded in individual animals. Inhibitory effects of VIP injected in the VM (upper) and PV (lower) at $1900 \mathrm{~h}$ are shown. For further details, see Fig. 2.

1,939 after VIP). In contrast, significantly inhibitory effects of VIP were caused when injected into the VM at $1900 \mathrm{~h}$ (Fig. 3). In rat No. 166, VIP injection at $1100 \mathrm{~h}$ produced a small but significant increase in the activity (the activity count after saline was 90 , although not shown in the figure, and that after VIP was 218 ), whereas the injection at $1900 \mathrm{~h}$ produced a significant decrease in the period 1900-2200 h (1,785 counts after saline, but 186 counts after VIP) and also in the period $1900-0500 \mathrm{~h}$. The injection at $1900 \mathrm{~h}$ into the PV in rat No. 187 also produced a decrease, in either the period $1900-2200 \mathrm{~h}(3,437$ counts after saline, but 1,692 after VIP, and in this case, VIP effects during the light cycle was not 
significant, although the data after saline is not shown in the figure) or the period $1900-0500 \mathrm{~h}$.

\section{DISCUSSION}

The hypermotility, which was produced by the intracerebroventricular injection of VIP in the rat during the light cycle (IтOH et al., 1985), was shown to be reproduced by the VIP injection in the VM and PV in the present study. It was then assumed that these hypothalamic nuclei somehow stimulate the motor activity in response to VIP in the light cycle. As mentioned before, the hypothalamic nuclei which we tested in the present study were almost those which have been shown to be involved in the control of feeding behavior and behavioral response to a variety of stimuli. Therefore, it is very probable that the effect of VIP on spontaneous motor activity will involve an effect on these behaviors. Further, the present study showed that the effect of VIP on the motor activity was reversed and therefore was inhibitory, when the injection was performed in the dark cycle. Then, the injection of VIP in the medial hypothalamus seemed to cause opposite effects on motor activity that depended on the time of day the peptide was injected.

There is increasing evidence to support VIP as a neurotransmitter or neuromodulator in the brain (Rosselin et al., 1982). In the hypothalamus, VIP has been shown to stimulate adenylate cyclase activity (QuIK et al., 1978; BORGHI et al., 1979) and alter neuronal electrical activity (HASKIns et al., 1982; AKEMA et al., 1986). When injected in the third ventricle, VIP affects the anterior pituitary hormone secretion, probably acting at the hypothalamus (VIJAYAN et al., 1979; AlEXANDER et al., 1985). Together with the finding that VIP has a marked regional distribution with considerably high levels in the hypothalamic nuclei (see review by PaLkovits, 1985), it is probable that VIP administered in the hypothalamus affected the neuronal activity acting as a neurotransmitter. However, a possibility cannot be denied that it has altered local metabolism in the hypothalamus by causing vasodilation of cerebral blood vessels (DUCKLES and SAID, 1982) and enhancing glucose utilization (MAGISTRETTI et al., 1981).

Although it has not been determined how injected VIP caused time-dependent effects on the neuronal activity, we propose two possibilities: first, injected VIP inhibited the neuronal activity of the PV and VM in the light cycle but facilitated it in the dark cycle, and second, injected VIP potentiated the response of PV and VM neurons to endogenous norepinephrine which was inhibition in the light cycle but facilitation in the dark cycle.

Taking the finding into consideration that rats with destruction of the medial hypothalamus overeat both in the light and dark cycle, not displaying a diurnal variation (AHLSKOG et al., 1975), whereas normal rats eat more food in the dark cycle, indicating that the medial hypothalamus is acting to inhibit feeding even in the light cycle, it was possible that injected VIP inhibited the neuronal activity in the medial hypothalamus in the light cycle whereas it facilitated it during the dark cycle. 
Such a time-dependent difference in the effect of VIP suggests an implication of influence of circadian rhythm mechanism whose center locates in the suprachiasmatic nucleus (MOORE, 1978). Namely, the suprachiasmatic nucleus contains a very dense concentration of VIP-reactive perikarya and gives fibers to some of the hypothalamic nuclei including the PV and VM (SIMS et al., 1980) and further, this region in the hypothalamus has been shown to provide the neuronal activity of many other regions with circadian rhythmicity which is generally low in the light cycle and high in the dark cycle (INOUYE and KAWAMURA, 1979). Taken together, there seems to be a possibility that an influence from the suprachiasmatic nucleus which is mediated by VIP fibers causes an inhibition in the light cycle and a facilitation in the dark cycle in the hypothalamic neuronal activity. Then, it was likely that the addition of exogenous VIP would have potentiated such endogenous VIP effects on these brain regions.

The second possibility is based on the assumption that norepinephrine, acting at the hypothalamic nucleus, causes time-dependent effects on feeding. When administered directly in the PV or VM during the light cycle, it induced feeding responses in satiated rats (Leibowitz, 1978; MatThews et al., 1978), and when administered in the lateral hypothalamus, it inhibited feeding during the light cycle and facilitated during the dark cycle (MARGules et al., 1972) in rats. Taking the finding into consideration that destruction of noradrenergic bundles with 6hydroxydopamine facilitated feeding only in the dark cycle (AHLSKOG et al., 1975), it seems that the noradrenergic transmission exerts, as a whole, an influence on the hypothalamic nuclei to prevent overeating in the dark cycle, whereas it exerts some facilitatory influence in the light cycle. On the VM and PV, the norepinephrine effect is assumed to be inhibitory in the light cycle but facilitatory in the dark cycle.

An existence of the synergism between VIP and norepinephrine has been suggested in the cerebral cortex, in which VIP and norepinephrine fiber systems have the same targets, the pyramidal cells (see review by BLOOM et al.,.1985). There, VIP alone causes either inhibitions, excitations, and no changes of neuronal discharges, whereas the effects on norepinephrine are predominantly inhibitory. However, if VIP was applied during administration of subthreshold norepinephrine, the norepinephrine effects were pronounced inhibitions of neuronal discharge regardless of the effect of VIP prior to norepinephrine; even in cases where VIP alone gave excitatory effects, concurrent subthreshold norepinephrine treatment reversed the VIP effect from excitation to inhibition, implying, in turn, that VIP acts to augment the action of norepinephrine on neuronal discharges in the cortex. Further, it was found that VIP and norepinephrine could act synergistically to increase adenylate cyclase in the cortical slices (MagistretTI and SCHORDERET, 1985). It is thus possible that the exogenous VIP administered will potentiate the action of endogenous norepinephrine on the neuronal activity of the PV and VM, which will be either facilitatory or inhibitory in the hypothalamus depending on the time of day, and thus will reveal its time-dependent effects, as far as feeding is concerned.

It is interesting to consider that the effects of VIP will probably change as a 
function of norepinephrine activity at the target neurons. It is possible that the first mechanism we raised for the reversed effects of VIP due to the time of day virtually involves this VIP-norepinephrine interaction at the levels of hypothalamic neurons. However, studies are needed to ascertain the mechanism for VIP effects on motor activity.

The authors are grateful to Ms. Kayoko Jinnai for her help with the data analysis.

\section{REFERENCES}

Ahlskog, J. E., Randall, P. K., and Hoebel, B. G. (1975) Hypothalamic hyperphagia: Dissociation from hyperphagia following destruction of noradrenergic neurons. Science, 190: 399-401.

Akema, T., Praputpittaya, C., and Kimura, F. (1986) Septalpreoptic unit responses to microelectrophoresis of cholecystokinin, gastrin, vasoactive intestinal peptide and secretion in the rat. Brain Res., 385: 366-370.

Albe-Fessard, D., Stutinsky, F., and Libouban, S. (1966) Atlas Stéréotaxique du Diencéphale du Rat Blanc, Editions du Centre National de la Recherche Scientifique, Paris.

Alexander, M. J., Clifton, D. K., and Steiner, R. A. (1985) Vasoactive intestinal polypeptide effects a central inhibition of pulsatile luteinizing hormone secretion in ovariectomized rats. Endocrinology, 117: 2134 2139.

Bloom, F. E., Battenberg, E., Ferron, A., Mancillas, J. R., Milner, R. J., Siggins, G., and Sutcliffe, J. G. (1985) Neuropeptides: Interactions and diversities. Rec. Prog. Horm. Res., 41: 339-367.

Borghi, C., Nicosia, S., Giachetti, A., and Said, S. I. (1979) Vasoactive intestinal polypeptide (VIP) stimulates adenylate cyclase in selected areas of rat brain. Life Sci., 24: $65-70$.

COlPAERT, F. C. (1975) The ventromedial hypothalamus and the control of avoidance behavior and aggression: Fear hypothesis versus response-suppression theory of limbic system function. Behav. Biol., 15: 27-44.

DuCKLES, S. P. and SAID, S. I. (1982) Vasoactive intestinal peptide as a neurotransmitter in the cerebral circulation. Eur. J. Pharmacol., 78: 317-374.

Grossman, S. P. (1972) Aggression, avoidance, and reaction to novel environments in female rats with ventromedial hypothalamic lesion. J. Comp. Physiol. Psychol., 78: 274-283.

Grossman, S. P. (1975) Role of the hypothalamus in the regulation of food and water intake. Psychol. Rev., 82: 200-224.

HaSkins, J. T., SAmSON, W. K., and Moss, R. L. (1982) Evidence for vasoactive intestinal polypeptide (VIP) altering the firing rate of preoptic, septal and midbrain central gray neurons. Reg. Peptide, 3: 113-123.

Heinbecker, P., White, H. L., and Rolf, D. (1944) Experimental obesity in the dog. Am. J. Physiol., 141: 549-565.

InOUYe, S.-I. T. and Kawamura, H. (1979) Persistence of circadian rhythmicity in a mammalian hypothalamic "island" containing the suprachiasmatic nucleus. Proc. Natl. Acad. Sci. U.S.A., 76: 5962-5966.

Itoh, S., Katsunra, G., and YoshiKawa, K. (1985) Hypermotility induced by vasoactive 
intestinal peptide in the rat: Its reciprocal action to cholecystokinin octapeptide. Peptides, 6: 53-57.

Leibowitz, S. F. (1978) Paraventricular nucleus: A primary site mediating adrenergic stimulation of feeding and drinking. Pharm. Biochem. Behav., 8: 163-175.

Leibowitz, S. F., Hammer, N. J., and Chang, K. (1981) Hypothalamic paraventricular nucleus lesions produce overeating and obesity in the rat. Physiol. Behav., 27: 10311040.

Magistretti, P. J., Morrison, J. H., Shoemaker, W. J., Sapin, V., and Bloom, F. E. (1981) Vasoactive intestinal polypeptide induces glycogenolysis in mouse cortical slices: A possible regulatory mechanism for the local control of energy metabolism. Proc. Natl. Acad. Sci. U.S.A., 78: 6535-6539.

Magistretti, P. J. and Schorderet, M. (1985) Norepinephrine and histamine potentiate the increase in cyclic adenosine $3^{\prime}: 5^{\prime}$-monophosphate elicited by vasoactive intestinal polypeptide in mouse cerebral cortical silices: Mediation by $\alpha_{1}$-adrenergic and $\mathrm{H}_{1}$ histaminergic receptors. J. Neurosci., 5: 362-368.

Margules, D. L., Lewis, M. J., Dragovich, J. A., and Margules, A. S. (1972) Hypothalamic norepinephrine: Circadian rhythms and the control of feeding behavior. Science, 178: 640-642.

Matthews, J. W., Booth, D. A., and Stolerman, I. P. (1978) Factors influencing feeding elicited by intracranial noradrenaline in rats. Brain Res., 141: 119-128.

Moore, R. Y. (1978) Central neural control of circadian rhythms. In: Frontiers in Neuroendocrinology, Vol. 5, ed. by GanONG, W. F. and Martin, L., Raven Press, New York, pp. 185-206.

Palkovits, M. (1985) Distribution of neuropeptides in the central nervous system: A review of biochemical mapping studies. Prog. Neurobiol., 23: 151-189.

QuiK, M., Iversen, L. L., and Bloom, S. R. (1978) Effect of vasoactive intestinal peptide (VIP) and other peptides on cAMP accumulation in rat brain. Biochem. Pharmacol., 27: 2209-2213.

Rosselin, G., Rotsztejn, W., Laburthe, M., and Dubois, P. M. (1982) Is VIP a neuroregulator or a hormone? In: Hormonally Active Brain Peptides; Structure and Function, ed. by McKerns, K. W. and Pantic, V., Plenum Press, New York, pp. 367395.

Rowley, T. L. (1977) The ventromedial hypothalamic syndrome, satiety, and a cephalic phase hypothetis. Psychol. Rev., 84: 89-126.

SePINWALl, J. (1969) Enhancement and impairment of avoidance behavior by chemical stimulation of the hypothalamus. J. Comp. Physiol. Psychol., 68: 393-399.

Sims, K. B., Hoffman, D. L., Said, S. I., and Zimmerman, E. A. (1980) Vasoactive intestinal polypeptide (VIP) in mouse and rat brain: An immunocytochemical study. Brain Res., 186: $165-183$.

Vijayan, E., Samson, W. K., Said, S. I., and McCann, S. M. (1979) Vasoactive intestinal peptide: Evidence for a hypothalamic site of action to release growth hormone, luteinizing hormone, and prolactin in conscious ovariectomized rats. Endocrinology, 104: $53-57$.

Weisman, R. N. and Hamilton, L. W. (1972) Two-way avoidance responding following VMH lesions: Effects of varying shock intensity. Physiol. Behav., 9: 243-246. 